19 Revue d'histoire du XIXe siècle

Société d'histoire de la révolution de 1848 et des

révolutions du XIXe siècle

$24 \mid 2002$

Varia

\title{
Hugh McLEOD, Secularisation in Western Europe,
}

1848-1914

London, Macmillan Press, 2000.

Miles Taylor

\section{(2) OpenEdition}

Journals

Édition électronique

URL : http://journals.openedition.org/rh19/398

DOI : 10.4000/rh19.398

ISSN : $1777-5329$

Éditeur

La Société de 1848

Édition imprimée

Date de publication : 1 juin 2002

Pagination : 207-208

ISSN : 1265-1354

Référence électronique

Miles Taylor, "Hugh McLEOD, Secularisation in Western Europe, 1848-1914 », Revue d'histoire du XIXe siècle [En ligne], 24 | 2002, mis en ligne le 04 juin 2003, consulté le 22 septembre 2020. URL : http:// journals.openedition.org/rh19/398; DOI : https://doi.org/10.4000/rh19.398

Ce document a été généré automatiquement le 22 septembre 2020

Tous droits réservés 


\section{Hugh McLEOD, Secularisation in Western Europe, 1848-1914}

London, Macmillan Press, 2000.

Miles Taylor

Comment, quand et pourquoi l'Europe moderne s'est-elle sécularisée ? C'est une question qui a longtemps embarrassé les historiens. La plupart s'accorderaient à dire que le processus était achevé à l'issue de la Première Guerre mondiale. Mais quant à savoir si c'est le socialisme, la science, l'urbanisation ou simplement l'indifférence, voire l'expérience de la catastrophe qu'a été la guerre sur le continent européen de 1914 à 1918, qui ont entraîné le déclin de la religion --c'est une question qui a divisé les chercheurs au cours des quarante dernières années. Une des voix les plus distinguées et les plus convaincantes est celle de l'historien britannique Hugh McLeod. Depuis 1974, il a publié une série d'ouvrages qui étudient en particulier la vie religieuse des classes laborieuses des grandes villes, d'abord en Grande-Bretagne, puis plus récemment dans d'autres métropoles d'Europe et d'Amérique du Nord. Ce qui a le plus caractérisé la contribution de McLeod à la production historique sur la sécularisation a été, premièrement, son insistance sur une approche comparative ; deuxièmement, sa réticence à isoler un facteur unique comme élément clé du changement religieux. Ces talents de synthèse et de discernement ressortent de nouveau dans le dernier livre de Hugh McLeod, Secularisation in Modern Europe, qui se concentre sur les différentes cultures religieuses de la France, de l'Allemagne et de l'Angleterre (mais pas de l'Écosse, du pays de Galles, ni de l'Irlande) au cours des quelque soixante années qui vont des révolutions de 1848 au début de la Première Guerre mondiale. McLeod nous livre ici une excellente introduction et une très bonne vue d'ensemble de la question. Il évoque les différentes explications de la sécularisation qui ont été avancées, résume l'abonde recherche récente (dont les conclusions de thèses nouvelles) en trois langues différentes, et fournit des études de cas et des détails éclairants à partir des pays et des confessions retenus.

Ce livre ne s'intéresse pas seulement aux confessions dominantes protestantes et catholique, mais aussi au judaïsme, au non-conformisme et aux religions alternatives comme le spiritualisme et même le socialisme. McLeod ne discute pas le rythme de la 
sécularisation, bien qu'il fasse des mises en garde salutaires contre la trop grande confiance accordée aux statistiques de l'assistance aux services religieux. Il ne conteste pas non plus les principales conclusions de la récente histoire sociale de la religion (notamment en Grande-Bretagne), à savoir qu'à mesure que les autorités locales et l'aide sociale se développaient, les fonctions temporelles et paroissiales des églises étaient marginalisées. Mais il insiste avec raison sur les éléments de continuité dans la vie religieuse de l'Europe, et montre, entre autres, comment l'Église catholique s'est adaptée en France au défi du républicanisme séculier, et a fait de la politique confessionnelle la force partisane qu'elle est restée pendant presque un siècle. Il développe aussi une idée abordée dans des travaux antérieurs, à savoir qu'une grande part de l'Europe serait seulement à "moitié sécularisée", et qu'un "christianisme de sens commun" y a survécu sous la forme de code moral, ou de cadre pour les rites de naissance, de mariage et de décès. McLeod se penche également sur les séries d'étranges renouveaux religieux et autres adorations de saints, qui se sont produits non seulement dans des zones rurales mais aussi dans des villes; il suggère que l'attrait de la magie et du folklore a accompagné la modernité. On regrette parfois que l'auteur n'ait pas étendu plus encore son champ d'étude, pour englober les monarchies catholiques de l'Espagne et de l'Italie ; et, bien que le sujet soit mentionné, il aurait été bon d'en savoir plus sur la façon dont l'exportation du zèle religieux vers les colonies européennes qui essaimaient outremer a remodelé l'évangélisme dans les métropoles. Dans l'ensemble, ce livre est une excellente et accessible introduction à la question. Il n'y a pas de réponses faciles, mais toutes les bonnes questions sont posées. 